\section{DNA Repair After Exposure to Ionizing Radiation Is Not Error-Free}

TO THE EDITOR: Contrary to Siegel et al.'s commentary (1), we find little reason to believe that "dose optimization to minimize radiation risk for children ... is misguided and detrimental." Although Siegel et al. acknowledge that ionizing radiation causes DNA double-strand breaks (DSBs) at the doses used for medical imaging, they fail to fully understand the consequences of such damage. The studies of Löbrich et al. and other investigators were designed to assess whether DNA strands were reconnected after exposure to ionizing radiation (2-4). Those studies did not assess the fidelity of repair at the level of the DNA sequence. Nonhomologous end joining (NHEJ) and homologous recombination are the principal pathways for repairing DSBs (5). Although NHEJ can occur during any phase of the cell cycle, it is error-prone (5-7). In contrast, whereas homologous recombination allows errorfree repair, it is restricted to the $\mathrm{S}$ and $\mathrm{G} 2$ phases of dividing cells since it uses the sequence found in the sister-chromatid as the template (5).

Multiple studies have demonstrated a linear dose-response relationship between exposure to ionizing radiation and DNA DSBs $(2,4,8)$. Given that even replicating cells spend most of their time in G1 phase, most DSBs will likely be repaired by NHEJ. Even during S and G2, most of the DSBs that are not related to genome replication are repaired by NHEJ (7). Since NHEJ typically leads to alterations in the underlying DNA sequence, we should expect that the fraction of cells with DNA mutations will steadily increase with dose. Deviations from this linear response are possible if cells containing mutations are preferentially lost by mechanisms such as programmed cell death (apoptosis). However, the prevailing paradigm is that the DNA in cells with minimal damage is repaired (albeit with mutations as described above) whereas cell death pathways are activated when repair fails or the damage exceeds the capacity of the repair systems (9). This would suggest that mutation would be favored over cell loss at low doses and low dose rates.

We acknowledge that DNA damage also occurs from other sources, such as reactive oxygen species. However, the available data indicate that such damage is usually less severe, since it results in single-strand breaks or base damage $(8,10-12)$. The redundancy provided by the double helical structure of DNA allows repair of such damage without alteration of the underlying DNA sequence. DSBs generated by ionizing radiation are considered particularly toxic since the ends are heterogeneous and not amenable to simple ligation $(6,7,10)$. As outlined above, repairing such DSBs typically leads to mutations.

Consider the following: the doses of ionizing radiation used for medical imaging cause an observable increase in DSBs; the increase in observed DSBs follows a linear dose-response relationship; the primary pathway used to repair DSBs, NHEJ, leaves permanent information scars in the genome; and the relationship between cancer causation and radiation exposure is linear once doses of ionizing radiation exceed $100 \mathrm{mGy}$ (10). Until molecular biology uncovers a causal chain that refutes the linear no-threshold model and those findings are supported by epidemiologic studies, we believe that it is misguided and detrimental to children not to optimize radiation exposure during medical imaging.

\section{REFERENCES}

1. Siegel JA, Sacks B, Pennington CW, Welsh JS. Dose optimization to minimize radiation risk for children undergoing $\mathrm{CT}$ and nuclear medicine imaging is misguided and detrimental. J Nucl Med. 2017;58:865-868.

2. Löbrich M, Rief N, Kuhne M, et al. In vivo formation and repair of DNA doublestrand breaks after computed tomography examinations. Proc Natl Acad Sci USA. 2005;102:8984-8989.

3. Halm BM, Franke AA, Lai JF, et al. Gamma-H2AX foci are increased in lymphocytes in vivo in young children $1 \mathrm{~h}$ after very low-dose $\mathrm{x}$-irradiation: a pilot study. Pediatr Radiol. 2014;44:1310-1317.

4. Asaithamby A, Chen DJ. Cellular responses to DNA double-strand breaks after low-dose gamma-irradiation. Nucleic Acids Res. 2009;37:3912-3923.

5. Jackson SP, Bartek J. The DNA-damage response in human biology and disease. Nature. 2009;461:1071-1078.

6. Lieber MR. The mechanism of double-strand DNA break repair by the nonhomologous DNA end-joining pathway. Annu Rev Biochem. 2010;79:181211.

7. Chang HHY, Pannunzio NR, Adachi N, Lieber MR. Non-homologous DNA end joining and alternative pathways to double-strand break repair. Nature Reviews Molecular Cell Biology website. https://www.nature.com/nrm/journal/vaop/ ncurrent/full/nrm.2017.48.html, Published May 17, 2017. Accessed November 22, 2017.

8. Grudzenski S, Raths A, Conrad S, Rube CE, Lobrich M. Inducible response required for repair of low-dose radiation damage in human fibroblasts. Proc Natl Acad Sci USA. 2010;107:14205-14210.

9. Roos WP, Thomas AD, Kaina B. DNA damage and the balance between survival and death in cancer biology. Nat Rev Cancer. 2016;16:20-33.

10. Committee to Assess Health Risks from Exposure to Low Level of Ionizing Radiation. Health Risks from Exposure to Low Levels of Ionizing Radiation: BEIR VII Phase 2. Washington, D.C.: National Academies Press; 2006.

11. Ward JF, Evans JW, Limoli CL, Calabro-Jones PM. Radiation and hydrogen peroxide induced free radical damage to DNA. Br J Cancer Suppl. 1987;8:105-112.

12. Ciccia A, Elledge SJ. The DNA damage response: making it safe to play with knives. Mol Cell. 2010;40:179-204.

James R. Duncan
Mallinckrodt Institute of Radiology
510 S. Kingshighway
St. Louis, MO 63110
E-mail: jrduncan@wustl.edu
Michael R. Lieber
USC Norris Comprehensive Cancer Center
Noritaka Adachi
Yokohama City University
Richard L. Wahl
Mallinckrodt Institute of Radiology

Published online Aug. 3, 2017.

DOI: 10.2967/jnumed.117.197673 